\title{
Early detection of ovarian and fallopian tube cancer by examination of cytological samples from the endometrial cavity
}

\author{
I Otsuka ${ }^{\star, 1}$, S Kameda ${ }^{1}$ and K Hoshi ${ }^{2}$ \\ ${ }^{1}$ Department of Gynecology, Kameda Medical Center, 929 Higashi-cho, Kamogawa, Chiba 296-8602, Japan and 2Department of \\ Pathology, Kameda Medical Center, 929 Higashi-cho, Kamogawa, Chiba 296-8602, Japan
}

Background: Accumulating evidence suggests that many ovarian high-grade serous carcinomas (HGSCs) originate in the fallopian tube. Malignant cells shed by tubal lesions can be detected by examination of cytological samples from the endometrial cavity (endometrial cytological testing). To evaluate the use of this method for detecting HGSC, we examined epithelial ovarian, fallopian tube, and primary peritoneal cancer patients.

Methods: Endometrial cytological testing was performed for endometrial cancer screening in asymptomatic women and for pre-treatment evaluation in symptomatic suspected ovarian, tubal, and peritoneal cancer patients.

Results: Of the 122 ovarian, tubal, and peritoneal cancer patients, malignant cells were identified in 5 patients who did not show detectable abnormalities on imaging studies. Cervicovaginal cytology was positive in only one of these five patients. Four patients were asymptomatic and one was symptomatic. Three asymptomatic patients had early-stage HGSCs, and the other asymptomatic patient had positive peritoneal cytology findings but no detectable tumour. HGSC patients were significantly more likely to have positive findings on endometrial cytology than patients with other histological types ( $23 \%$ vs $6 \%, P=0.02)$.

Conclusion: Endometrial cytological testing can detect early-stage ovarian, tubal, and peritoneal HGSCs without detectable pelvic masses and may be useful for ovarian cancer screening.

Ovarian cancer is the most lethal gynaecological malignancy, because most patients are not diagnosed until the disease is at an advanced stage. However, prognosis is favourable if diagnosed when the disease is confined to the ovary. Therefore, a screening method that facilitates early detection has been actively sought (Clarke-Pearson, 2009). Two diagnostic tests, transvaginal ultrasonography and the serum cancer antigen (CA)-125 assay, have been used for ovarian cancer screening (Stirling et al, 2005; Lacey et al, 2006; Hermsen et al, 2007; van Nagell et al, 2007; Menon et al, 2009; Buys et al, 2011). These two diagnostic tests have been able to detect many cases of early-stage ovarian cancer; however, a recent randomised study using these two tests failed to show mortality reduction (Buys et al, 2011), the critical metric for screening success. That study also indicated that diagnostic evaluation following a false-positive screening test result was associated with increased morbidity.

The premise underlying the early detection of ovarian cancer by ultrasonography is the presence of a detectable ovarian mass. Lowgrade serous, endometrioid, clear cell, and mucinous carcinomas develop from detectable precursor lesions in the ovary (Horiuchi et al, 2003, Shih and Kurman, 2004). However, accumulating evidence suggests that this premise is inaccurate for many cases of high-grade serous carcinoma (HGSC). A large proportion of serous carcinomas have been shown to develop from tiny lesions in the fallopian tube (Cass et al, 2005; Powell et al, 2005; Finch et al, 2006; Medeiros et al, 2006; Callahan et al, 2007; Kindelberger et al, 2007),

*Correspondence: Dr I Otsuka; E-mail: i.otsuka@kameda.jp

Received 17 March 2013; revised 24 June 2013; accepted 26 June 2013; published online 18 July 2013 
not in the ovary, and the vast majority of serous carcinomas are high grade (Shih and Kurman, 2004; Prat, 2012). Thus, screening using transvaginal ultrasonography and the CA-125 assay is ineffective for the early detection of most HGSCs (Hermsen et al, 2007; Gilbert et al, 2012). Because HGSC is the most common and the most lethal type of ovarian cancer (Gilbert et al, 2012), early detection of HGSC is necessary for reducing mortality due to ovarian cancer.

If most HGSCs arise in the fallopian tube, malignant cells shed by these cancers can be detected by the examination of cytological samples from the endometrial cavity (endometrial cytological testing), a concept similar to that for the detection of cervical cancers by Papanicolaou smears. Several case reports have shown that endometrial cytological tests developed to screen endometrial cancer (Ferenczy and Gelfand, 1984; Byrne, 1990) can detect intraepithelial and microinvasive fallopian tube carcinomas (Ikarashi et al, 1995; Luzzatto et al, 1996; Minato et al, 1998; Gocho et al, 2009, Maeda et al, 2010). In Japan, endometrial cancer screening using such cytological tests is widely performed for women at risk of the disease (Tsuda et al, 1997), including breast cancer patients treated with tamoxifen (Gocho et al, 2009; Otsuka et al, 2010), and women who request the screening. In the present study, we examined the data of patients with epithelial ovarian, fallopian tube, and primary peritoneal cancer to evaluate the role of endometrial cytological testing in detecting HGSC, particularly for screening setting.

\section{PATIENTS AND METHODS}

A consecutive series of patients with epithelial ovarian, fallopian tube, or primary peritoneal cancer diagnosed and treated at the Department of Gynecology, Kameda Medical Center, Kamogawa, Chiba, Japan between January 2000 and July 2011 were identified from the tumour registry, and their medical records were reviewed to obtain clinical and pathological data. Of these patients, those who underwent pre-treatment endometrial and cervicovaginal cytological tests were included in this study. Patients with synchronous endometrioid endometrial cancer or patients with borderline ovarian tumour were excluded.

For endometrial cytological evaluation, samples were obtained from the endometrial cavity using a disposable plastic brush (endometrial sampler) as previously described by other authors (Ferenczy and Gelfand, 1984; Byrne, 1990). The samples obtained were smeared directly on slides for fixation and staining. In this study, a positive result was defined as the detection of malignant cells on cytological tests, and a suspicious result was defined as the identification of atypical but not malignant cells.

In asymptomatic women, endometrial cytological tests were performed to screen for endometrial cancer in addition to pelvic examination and cervicovaginal smears for cervical cancer screening. According to the records examined in this study, imaging studies such as transvaginal ultrasonography were also performed in some women. Symptomatic women with suspected ovarian, fallopian tube, or primary peritoneal cancer who visited the clinic underwent both endometrial cytological and cervicovaginal cytological tests, in addition to physical examination and transvaginal ultrasonography. For these symptomatic cases, cytological testing was performed to determine the nature of their disease before treatment. Endometrial and endocervical curettage was performed for women with positive or suspicious results on endometrial cytological testing to histologically confirm or rule out a diagnosis of endometrial cancer. Both asymptomatic women with screen-detected abnormalities and symptomatic women with suspected ovarian, fallopian tube, or primary peritoneal cancer underwent pre-treatment evaluation that included a serum CA-125 assay and imaging studies such as computed tomography (CT) of the abdomen and pelvis, as well as pelvic magnetic resonance imaging. In the recent past, whole-body positron emission tomography -CT has been performed instead of CT for some patients. In patients with bulky metastatic diseases (presumed stage III or IV) that did not appear to be optimally debulked by primary surgery, neoadjuvant chemotherapy was performed. Statistical analysis of the results was performed using the chi-square test and the Fisher's exact test.

\section{RESULTS}

Of the 188 patients with ovarian, fallopian tube, or primary peritoneal cancer who were diagnosed and treated during the study period, 122 patients underwent both endometrial and cervicovaginal cytological tests. The median age of the patients was 59 years (range, 33-83 years). Stage distribution was as follows: stage I, 37 patients (30\%); stage II, 12 patients (10\%); stage III, 60 patients (49\%); and stage IV, 12 patients (10\%) (Table 1). The remaining patient was classified as stage 0 , because pathological examination showed no source of cancer in either the ovaries or fallopian tubes, but positive findings were observed for adenocarcinoma cells on peritoneal cytology. Forty-four patients (36\%) had high-grade (grade 2-3) serous carcinoma. Seventy-eight patients had nonHGSC: 8 patients (7\%) had low-grade serous carcinoma, 3 patients (2\%) had non-gradable serous carcinoma, 32 patients $(26 \%)$ had endometrioid carcinoma, 15 patients (12\%) had clear cell carcinoma, 10 patients (8\%) had mucinous carcinoma, and 10 patients $(8 \%)$ had other histological types (including 1 patient with no detected source of carcinoma). Twelve patients (10\%) were asymptomatic (screen-detected) (Table 2) and 110 patients (90\%) were symptomatic.

Of the 122 patients, malignant cells were identified by cytological examination of samples from the endometrial cavity in 5 patients without detectable abnormalities on imaging studies. The characteristics of these five patients are listed in Table 3. Cytological examination was performed at other institutions for four asymptomatic patients and at our clinic for one symptomatic patient. We have previously reported on this symptomatic patient (Ohta et al, 2009).

In all the four asymptomatic patients with screen-detected ovarian, fallopian tube, or primary peritoneal cancer, endometrial cytological testing was positive for malignant cells, whereas cervicovaginal cytological testing was positive in only one of these patients. Two patients (cases 1 and 3 ) underwent surgery before the detection of abnormal findings on imaging studies. The case 1 patient underwent surgery 2 months after cytological detection; however, no source of cancer was detected (stage 0 ). This patient subsequently developed peritoneal carcinomatosis 3 years after primary treatment. In the other three patients, treatment was delayed, because their conditions could not be confirmed as gynaecological malignancy as repeated endometrial cytological testing results were not positive. One patient (case 3) had an elevated CA-125 level at the time of cytological testing (47 $\mathrm{U} \mathrm{ml}^{-1}$ ); however, her CA-125 levels spontaneously decreased and remained within the normal range $\left(\leqslant 17 \mathrm{U} \mathrm{ml}^{-1}\right)$ throughout the course of the study. All four diseases were diagnosed at an early stage (stage $0-\mathrm{II}$ ), and three gross tumours were diagnosed as HGSC by microscopic examination.

Of the 122 patients, endometrial cytological testing was positive in 15 patients (12\%), including 5 patients (4\%) who showed positive results on cervicovaginal cytology. Six of these 15 patients (40\%) were diagnosed with early-stage disease (stage 0-II) (Table 1). Patients with HGSC were significantly more likely to 
Table 1. Endometrial cytology results for high-grade serous and non-high-grade serous carcinoma

\begin{tabular}{|c|c|c|c|c|c|}
\hline & & \multicolumn{2}{|c|}{ High-grade serous carcinoma } & \multicolumn{2}{|c|}{ Non-high-grade serous carcinoma } \\
\hline & $\begin{array}{c}\text { Total } \\
(n=122)\end{array}$ & $\begin{array}{c}\text { Total } \\
(n=44)\end{array}$ & $\begin{array}{l}\text { Positive endometrial } \\
\text { cytology }(n=10)\end{array}$ & $\begin{array}{c}\text { Total } \\
(n=78)\end{array}$ & $\begin{array}{l}\text { Positive endometrial } \\
\text { cytology }(n=5)\end{array}$ \\
\hline \multicolumn{6}{|l|}{ Stage } \\
\hline $\begin{array}{l}0 \\
\text { I } \\
\text { II } \\
\text { III } \\
\text { IV }\end{array}$ & $\begin{array}{l}1^{\mathrm{a}} \\
37 \\
12 \\
60 \\
12\end{array}$ & $\begin{array}{r}0 \\
6 \\
4 \\
31 \\
3\end{array}$ & \begin{tabular}{l}
\multicolumn{1}{c}{0} \\
$1(17 \%)$ \\
$2(50 \%)$ \\
$7(23 \%)$ \\
$0(0 \%)$
\end{tabular} & $\begin{array}{r}1 \\
31 \\
8 \\
29 \\
9\end{array}$ & $\begin{array}{c}1(100 \%) \\
0(0 \%) \\
2^{b}(25 \%) \\
2^{c}(7 \%) \\
0(0 \%)\end{array}$ \\
\hline \multicolumn{6}{|l|}{ Ascites } \\
\hline $\begin{array}{l}\text { None to minimal } \\
\text { Moderate to } \\
\text { massive }\end{array}$ & $\begin{array}{l}84 \\
38\end{array}$ & $\begin{array}{l}22 \\
22\end{array}$ & $\begin{array}{l}6(27 \%) \\
4(18 \%)\end{array}$ & $\begin{array}{l}62 \\
16\end{array}$ & $\begin{array}{l}4(6 \%) \\
1(6 \%)\end{array}$ \\
\hline \multicolumn{6}{|c|}{ Peritoneal cytology } \\
\hline $\begin{array}{l}\text { Positive } \\
\text { Suspicious } \\
\text { Negative } \\
\text { Unknown }\end{array}$ & $\begin{array}{r}49 \\
7 \\
60 \\
6\end{array}$ & $\begin{array}{r}28 \\
2 \\
11 \\
3\end{array}$ & $\begin{array}{l}8(29 \%) \\
0(0 \%) \\
1(9 \%) \\
1(33 \%)\end{array}$ & $\begin{array}{r}21 \\
5 \\
49 \\
3\end{array}$ & $\begin{array}{l}3(14 \%) \\
0(0 \%) \\
1(2 \%) \\
1(33 \%)\end{array}$ \\
\hline
\end{tabular}

have positive findings on endometrial cytology (10 out of $44,23 \%)$ than those with other histological types (5 out of $78,6 \% ; P=0.02$ ). In the cases of low-grade serous or mucinous carcinomas, we found no positive or suspicious endometrial cytological findings.

Upon examination of the family history of 101 patients, we found that positive findings were observed on endometrial cytology more frequently in women who had a first-degree relative with breast or ovarian cancer ( 5 out of $12,42 \%$ ) than in women who did not (9 out of $89,10 \% ; P=0.01$ ). Of the five women with family histories of breast or ovarian cancer and positive findings on endometrial cytology, HGSC was observed in four and clear cell carcinoma was observed in one.

\section{DISCUSSION}

The findings of this study indicate that endometrial cytological testing can facilitate the detection of preclinical early-stage epithelial ovarian, fallopian tube, and primary peritoneal HGSCs during screening. Patients with HGSCs are more likely to have positive cytology findings than those with other histological types.

Epithelial ovarian cancers are heterogeneous and are classified into five main types: high-grade serous, low-grade serous, endometrioid, clear cell, and mucinous tumours (Prat, 2012). These types are essentially distinct diseases as indicated by the differences in epidemiological and genetic risk factors, precursor lesions, patterns of spread, and molecular events during tumourigenesis (Shih and Kurman, 2004; Prat, 2012). Low-grade serous, endometrioid, clear cell, and mucinous carcinomas develop from detectable precursor lesions in the ovary, such as borderline tumours and endometriotic cysts (Horiuchi et al, 2003; Shih and Kurman, 2004). In contrast, many HGSCs appear to develop from tiny lesions in the fallopian tube.

A tubal origin of many HGSCs is supported by the following observations: (1) identification of the fallopian tube as a frequent source of early serous carcinoma on assessment of prophylactic salpingo-oophorectomy specimens from women with a germline mutation in the ovarian and breast carcinoma susceptibility genes (BRCA1 or BRCA2) (Powell et al, 2005; Finch et al, 2006); (2) detection of serous carcinomas localised to the distal fallopian tube on microscopic examination of the entire fallopian tube in both BRCA-positive and BRCA-negative women (Cass et al, 2005; Finch et al, 2006; Medeiros et al, 2006; Callahan et al, 2007; Kindelberger et al, 2007); and (3) identification of fallopian tube cancers more often than previously recorded in women at risk for developing ovarian cancer who undergo screenings using ultrasonography and the CA-125 assay (Fishman et al, 2005; Lacey et al, 2006; Gilbert et al, 2012). Moreover, precursor lesions of epithelial cancer were found in the fallopian tube (tubal intraepithelial carcinoma (TIC)) (Callahan et al, 2007; Kindelberger et al, 2007; Lee et al, 2007) but not on the ovarian surface (Barakat et al, 2000) in women with $B R C A$ mutations who underwent prophylactic salpingo-oophorectomy. TIC is a lesion of several cell layers on the tubal mucosa and is a plausible precursor for many pelvic (ovarian, fallopian tube, and primary peritoneal) serous carcinomas (Kindelberger et al, 2007; Lee et al, 2007; Seidman et al, 2011). Thus, screening tests need to be able to detect this microscopic lesion before it develops into a detectable mass and metastasises to the ovarian surface and/or pelvic peritoneum. Accordingly, ultrasonography screening cannot effectively detect HGSCs at an early stage, whereas other ovarian tumour histotypes, which remain in the ovary for an extended period, can be detected.

Serum CA-125 screening appears to be more effective than ultrasonography for detecting HGSC (Gilbert et al, 2012). However, most HGSCs detected on the basis of elevated CA-125 levels are at an advanced stage (Buys et al, 2011; Gilbert et al, 2012), and therefore, CA-125 testing is not useful for detecting early-stage HGSCs.

Cytological testing of samples from the endometrial cavity is more useful than cervicovaginal cytological testing for detecting malignant cells shed by fallopian tube cancer. A study on fallopian tube carcinomas, most of which were presumed to be HGSCs, showed that the incidence of positive endometrial cytology 


\begin{tabular}{|c|c|c|c|}
\hline & & \multicolumn{2}{|c|}{ Detection method } \\
\hline & $\begin{array}{c}\text { Total } \\
(n=12)\end{array}$ & $\begin{array}{l}\text { Endometrial } \\
\text { cytology }^{a} \\
(n=4)\end{array}$ & $\begin{array}{c}\text { Imaging studies/ } \\
\text { pelvic examination } \\
\left(n=8^{b}\right)\end{array}$ \\
\hline \multicolumn{4}{|l|}{ Age, years } \\
\hline $\begin{array}{l}\text { Range } \\
\text { Median }\end{array}$ & $\begin{array}{c}54-69 \\
62\end{array}$ & $\begin{array}{c}54-69 \\
57\end{array}$ & $\begin{array}{c}58-69 \\
64\end{array}$ \\
\hline \multicolumn{4}{|l|}{ Stage } \\
\hline $\begin{array}{l}0 \\
\text { I } \\
\text { II } \\
\text { III } \\
\text { IV }\end{array}$ & $\begin{array}{l}1 \\
2 \\
4 \\
3 \\
2\end{array}$ & $\begin{array}{l}1^{\mathrm{c}} \\
1 \\
2 \\
0 \\
0\end{array}$ & $\begin{array}{l}0 \\
1 \\
2 \\
3 \\
2\end{array}$ \\
\hline \multicolumn{4}{|l|}{ Histology } \\
\hline $\begin{array}{l}\text { High-grade serous } \\
\text { Non-high-grade } \\
\text { serous }\end{array}$ & $\begin{array}{l}6 \\
6\end{array}$ & $\begin{array}{r}3 \\
1^{c}\end{array}$ & $\begin{array}{r}3 \\
5^{d}\end{array}$ \\
\hline \multicolumn{4}{|c|}{ First-degree family history of breast and/or ovarian cancer } \\
\hline $\begin{array}{l}\text { Yes } \\
\text { No } \\
\text { Not available }\end{array}$ & $\begin{array}{l}5 \\
6 \\
1\end{array}$ & $\begin{array}{l}1 \\
3 \\
0\end{array}$ & $\begin{array}{l}4 \\
3 \\
1\end{array}$ \\
\hline \multicolumn{4}{|c|}{$\begin{array}{l}{ }^{a} \text { No abnormal findings on imaging studies. } \\
b_{\text {Six tumours were detected by ultrasound, } 1 \text { by PET-CT (positron emission tomography- }} \text { computed tomography), and } 1 \text { by pelvic examination. } \\
{ }^{c} \text { No source of cancer was detected. } \\
d_{\text {Endometrioid, } 2 \text {; clear cell, } 2 \text {; and low-grade serous, } 1 .}\end{array}$} \\
\hline
\end{tabular}

findings (positive for malignant cells) was twice as high as that of positive cervicovaginal cytology findings ( $50 \%$ vs $25 \%$; Takeshima et al, 1997). Although ovarian cancer has not been thought to be associated with positive cervical cytology (Vikki et al, 1998), a study on ovarian cancer showed that cervical cytology findings were positive in $19.3 \%$ of patients, which was less than half of the rate of positive findings on endometrial cytology (41.9\%; Takashina et al, 1988). However, the definition of positive cytological findings in that study was not available. A later study on ovarian cancer from the same institution showed lower incidences of positive findings on cytology (positive for adenocarcinoma cells): $11.7 \%$ for endometrial and $6.1 \%$ for cervical cytology (Suzuki et al, 2010). In our study, which includes ovarian, fallopian tube, and primary peritoneal cancers, the incidence of positive findings on endometrial cytology was three times as high as that of positive findings on cervicovaginal cytology (12\% vs 4\%). Differences in positive rates among studies may reflect the difficulty in interpreting cytological findings.

Of note, histological examinations of tissue samples obtained by endometrial curettage could not detect preclinical ovarian, fallopian tube, or primary peritoneal cancer in our study (Table 3), thereby highlighting the importance of cytological testing for the detection of malignant cells shed by the adnexal lesions and present in the endometrial cavity. In contrast, in all the eight patients with endometrial cancer who did not show detectable abnormalities on transvaginal ultrasonography during the same period, the endometrial cancer was diagnosed by histological examination of tissue samples obtained by endometrial curettage. Of the 179 postmenopausal endometrial cancer patients,
$8(4.5 \%)$ did not show detectable abnormalities (an endometrial thickness $\leqslant 5 \mathrm{~mm}$; Jacobs et al, 2011): 5 patients presented with vaginal bleeding and 3 patients without bleeding showed abnormal findings on endometrial cytological testing (data not shown).

Our study showed that women with family histories of breast or ovarian cancer were more likely to have positive cytology findings than women without such histories. Thus, endometrial cytological testing appears to be useful in these women, that is, women with a hereditary predisposition to ovarian cancer.

Endometrial cytological testing as an early detection method for HGSCs offers several advantages. First, this testing can detect HGSCs before they develop into a detectable mass. Even if HGSCs cannot be diagnosed at stage I, it is possible that they may be detected at a stage of low-volume disease, when they are still completely resectable. Second, direct sampling of tumour cells enables a cytology-based diagnosis. A high positive predictive value is expected when the lesion has progressed to HGSC with cells showing marked nuclear atypia. In addition, this cytological testing can be used in premenopausal women who tend to exhibit falsepositive abnormalities on ultrasonography scans and CA-125 assays. Moreover, endometrial cytological smears are inexpensive, well tolerated by patients, and easily performed by gynaecologists in clinical settings (Ferenczy and Gelfand, 1984; Byrne, 1990; Tsuda et al, 1997). Finally, this testing can detect endometrial carcinomas, which sometimes develop in women with breast cancer. However, in women with cervical stenosis, which is observed more often in elderly women, this method cannot be used.

In our study, the positive rate of endometrial cytological testing for stage I HGSC was low (1 out of $6,17 \%$ ). All six patients were diagnosed with ovarian carcinoma and five of them had an ovarian mass. An explanation for this low positive rate is that tubal occlusion caused by compression due to an ovarian mass or by tubal elongation associated with ovarian enlargement prevents clusters of cancer cells from flowing into the endometrial cavity. Another explanation is that some ovarian HGSCs arise from serous borderline tumour and low-grade serous carcinoma (Dehari et al, 2007), both of which are thought to develop within the cortical inclusion cyst of the ovary.

Several limitations of this study should be noted, in addition to the selection bias inherent to most retrospective reviews. First, pathological examination of TICs was not performed in all cases; therefore, the percentage of HGSCs that developed in the fallopian tube was unknown. However, the incidence of positive findings on endometrial cytology for HGSCs in our study (23\%) was similar to that for TICs coexisting in these tumours (36\%) (Roh et al, 2010), taking into consideration the difficulty of cytological evaluation and possible sampling errors. Second, the sensitivity, specificity, and positive and negative predictive values of endometrial cytological testing could not be calculated accurately, because the screening status was not known in all the patients. In our study, at least 4 patients who underwent annual endometrial cytological testing were diagnosed with HGSC at an interval of 2-6 months after negative screening ( 1 stage IIc and 3 stage IIIc diseases), and thus sensitivity was estimated at 43\% (3 out of 7) or less for HGSC. Third, BRCA testing, which is still uncommon in Japan partly because its high cost is not covered by health insurance, was not performed for any patients in this study. Therefore, the association between positive findings on endometrial cytology and $B R C A$ mutation status could not be assessed.

Finally, and importantly, whether endometrial cytological testing can detect carcinomas early enough to improve outcome has yet to be determined. Cancer cells arising from the fallopian tube may have already spread throughout the peritoneal cavity even if the original lesion is intraepithelial or microinvasive carcinoma. Little information regarding long-term outcomes is available for most reported cases of cytology-detected fallopian 


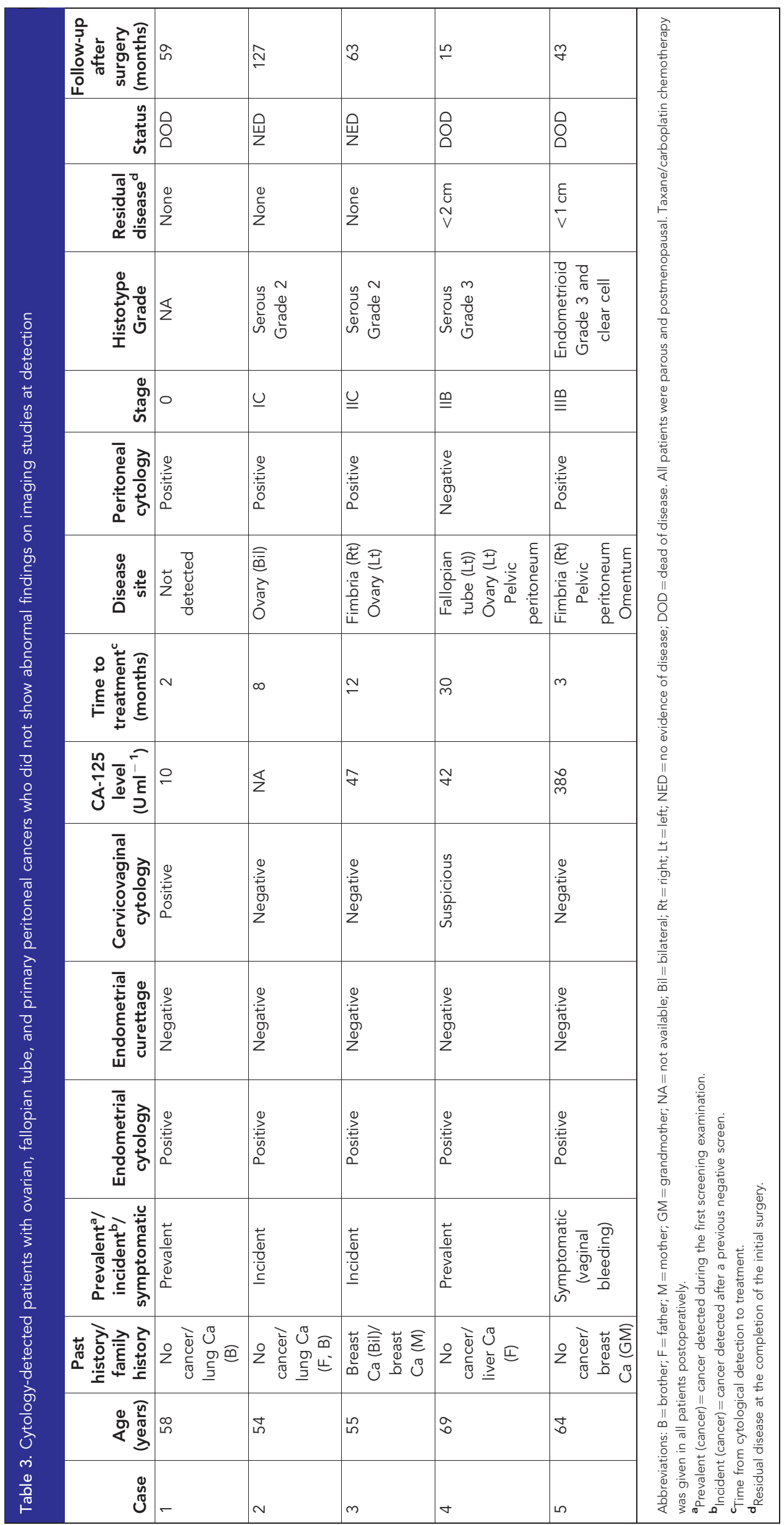


tube cancer. However, a patient with serous TIC with positive findings on peritoneal cytology, who also had a personal history of breast cancer, survived for $>7$ years despite two recurrences (Gocho et al, 2009). In our study, two of the four asymptomatic cytology-detected patients survived for $\geqslant 5$ years without a recurrence, even with delayed treatment.

In conclusion, efforts to detect early 'ovarian' cancer should focus on detecting the most common and the most lethal type: HGSC. To detect HGSCs, many of which arise in the fallopian tube, examination of cytological samples from the endometrial cavity appears to be a promising method. High-grade endometrioid carcinomas, which have been reported to develop in the fallopian tube (Medeiros et al, 2006; Callahan et al, 2007, Ohta et al, 2009), may also be detected using this method. Although the sensitivity of this method may not be sufficiently high on using conventional cytological evaluation methods, the use of p53 staining, which can detect atypical cells in TIC and its precursor lesions (Piek et al, 2001; Cass et al, 2005; Medeiros et al, 2006; Lee et al, 2007), may be helpful for early diagnoses. Use of an aspiration method in combination with a brush method for obtaining cytological samples from the endometrial cavity may improve the detection rates of malignant cells. The effectiveness of endometrial cytological testing for early-stage HSGC detection may be evaluated by using this method as a preoperative test for prophylactic bilateral salpingo-oophorectomy in women at risk for developing HGSC. For women with a BRCA mutation or family histories of breast or ovarian cancer who hope to undergo ovarian cancer screening, this testing method may be used as a surveillance test in combination with transvaginal ultrasonography and the serum CA-125 assay to compare the effectiveness of these tests for HGSC detection. Thus, limiting screening to high-risk women may reduce the burden of diagnostic procedures. Further studies are needed to address the issues of early detection using this method, the acceptability of this technique, and the health economics associated with this testing method before it is incorporated into an ovarian cancer screening randomised controlled trial to evaluate its effect on reducing mortality due to the disease.

\section{CONFLICT OF INTEREST}

The authors declare no conflict of interest.

\section{REFERENCES}

Barakat RR, Federici MG, Saigo PE, Robson ME, Offit K, Boyd J (2000) Absence of premalignant histologic, molecular, or cell biologic alterations in prophylactic oophorectomy specimens from BRCA1 heterozygotes. Cancer 89: 383-390.

Buys SS, Partridge E, Black A, Johnson CC, Lamerato L, Isaacs C, Reding DJ, Greenlee RT, Yokochi LA, Kessel B, Crawford ED, Church TR, Andriole GL, Weissfeld JL, Fouad MN, Chia D, O'Brien B, Ragard LR, Clapp JD, Rathmell JM, Riley TL, Hartge P, Pinsky PF, Zhu CS, Izmirlian G, Kramer BS, Miller AB, Xu JL, Prorok PC, Gohagan JK, Berg CD. for the PLCO Project Team (2011) Effect of screening on ovarian cancer mortality. The Prostate, Lung, Colorectal and Ovarian (PLCO) cancer screening randomized controlled trial. JAMA 305: 2295-2303.

Byrne AJ (1990) Endocyte endometrial smears in the cytodiagnosis of endometrial carcinoma. Acta Cytol 34: 373-381.

Callahan MJ, Crum CP, Medeiros F, Kindelberger DW, Elvin JA, Garber JE, Feltmate CM, Berkowitz RS, Muto MG (2007) Primary fallopian tube malignancies in BRCA-positive women undergoing surgery for ovarian cancer risk reduction. J Clin Oncol 25: 3985-3990.

Cass I, Holschneider C, Datta N, Barbuto D, Walts AE, Karlan BY (2005) BRCA-mutation-associated fallopian tube carcinoma. A distinct clinical phenotype? Obstet Gynecol 106: 1327-1334.
Clarke-Pearson DL (2009) Screening for ovarian cancer. N Engl J Med 361: 170-177.

Dehari R, Kurman RJ, Loghani S, Shih IM (2007) The development of highgrade serous carcinoma from atypical proliferative (borderline) serous tumors and low-grade micropapillary serous carcinoma: a morphologic and molecular genetic analysis. Am J Surg Pathol 31: 1007-1012.

Ferenczy A, Gelfand MM (1984) Outpatient endometrial sampling with Endocyte: comparative study of its effectiveness with endometrial biopsy. Obstet Gynecol 63: 295-302.

Finch A, Shaw P, Rosen B, Murphy J, Narod SA, Colgan TJ (2006) Clinical and pathologic findings of prophylactic salpingo-oophorectomies in 159 BRCA1 and BRCA2 carriers. Gynecol Oncol 100: 58-64.

Fishman DA, Cohen L, Blank SV, Shulman L, Singh D, Bozorgi K, Tamura R, Timor-Tritsch I, Schwartz PE (2005) The role of ultrasound evaluation in the detection of early-stage epithelial ovarian cancer. Am J Obstet Gynecol 192: 1214-1222.

Gilbert L, Basso O, Sampalis J, Karp I, Martins C, Feng J, Piedimonte S, Quintal L, Ramanakkumar AV, Takefman J, Grigorie MS, Artho G, Krishnamurthy S. for the DOvE Study Group (2012) Assessment of symptomatic women for early diagnosis of ovarian cancer: results from the prospective DOvE pilot project. Lancet Oncol 13: 285-291.

Gocho R, Nakamura E, Miyagawa K, Kanemoto J, Shimizu T, Kawaguchi K (2009) Fallopian tube adenocarcinoma in situ associated with adjuvant Tamoxifen therapy. a case report (in Japanese). J Jpn Soc Clin Cytol 48: 216-219.

Hermsen BBJ, Olivier RI, Verheijen RHM, van Beurden M, de Hullu JA, Massuger LF, Burger CW, Brekelmans CT, Mourits MJ, de Bock GH, Gaarenstroom KN, van Boven HH, Mooij TM, Rookus MA (2007) No efficacy of annual gynaecological screening in BRCA1/2 mutation carriers; an observational follow-up study. Br J Cancer 96: 1335-1342.

Horiuchi A, Itoh K, Shimazu M, Nakai I, Yamazaki T, Kimura K, Suzuki A, Shiozawa T, Ueda N, Konishi I (2003) Toward understanding the natural history of ovarian carcinoma development: a clinicopathological approach. Gynecol Oncol 88: 309-317.

Ikarashi H, Kodama S, Yoshiya N, Tanaka K, Nagai E, Emura I, Watanabe T, Sugai M (1995) Case report of carcinoma in situ of the fallopian tube found by mass screening for uterine cancer (in Japanese). J Jpn Soc Clin Cytol 34: 666-669.

Jacobs I, Gentry-Maharaj A, Burnell M, Manchanda R, Singh N, Sharma A, Ryan A, Seif MW, Amso NN, Turner G, Brunell C, Fletcher G, Rangar R, Ford K, Godfrey K, Lopes A, Oram D, Herod J, Williamson K, Scott I, Jenkins H, Mould T, Woolas R, Murdoch J, Dobbs S, Leeson S, Cruickshank D, Skates SJ, Fallowfield L, Parmar M, Campbell S, Menon U (2011) Sensitivity of transvaginal ultrasound screening for endometrial cancer in postmenopausal women: a case-control study within the UKCTOCS cohort. Lancet Oncol 12: 38-48.

Kindelberger DW, Lee Y, Miron A, Hirsch MS, Feltmate C, Medeiros F, Callahan MJ, Garner EO, Gordon RW, Birch C, Berkowitz RS, Muto MG, Crum CP (2007) Intraepithelial carcinoma of the fimbria and pelvic serous carcinoma: evidence for a causal relationship. Am J Surg Pathol 31: 161-169.

Lacey Jr JV, Greene MH, Buys SS, Reding D, Riley TL, Berg CD, Fagerstrom RM, Hartge P (2006) Ovarian cancer screening in women with a family history of breast or ovarian cancer. Obstet Gynecol 108: 1176-1184.

Lee Y, Miron A, Drapkin R, Nucci MR, Medeiros F, Saleemuddin A, Garber J, Birch C, Mou H, Gordon RW, Cramer DW, McKeon FD, Crum CP (2007) A candidate precursor to serous carcinoma that originates in the distal fallopian tube. J Pathol 211: 26-35.

Luzzatto R, Sisson G, Luzzatto L, Recktenvald M, Brucker N (1996) Psammoma bodies and cells from in situ fallopian tube carcinoma in endometrial smears: a case report. Acta Cytol 40: 295-298.

Maeda D, Takazawa Y, Ota S, Yakeuchi Y, Seta A, Nakagawa S, Yano T, Taketani Y, Fukayama M (2010) Bilateral microscopic adenocarcinoma of the fallopian tubes detected by an endometrial cytologic smear. Int J Gynecol Pathol 29: 273-277.

Medeiros F, Muto MG, Lee Y, Elvin JA, Callahan MJ, Feltmate C, Garber JE, Cramer DW, Crum CP (2006) The tubal fimbria is a preferred site for early adenocarcinoma in women with familial ovarian cancer syndrome. Am J Surg Pathol 30: 230-236.

Menon U, Gentry-Maharaj A, Hallett R, Ryan A, Burnell M, Sharma A, Lewis S, Davies S, Philpott S, Lopes A, Godfrey K, Oram D, Herod J, Williamson K, Seif MW, Scott I, Mould T, Woolas R, Murdoch J, 
Dobbs S, Amso NN, Leeson S, Cruickshank D, Mcguire A, Campbell S, Followfield L, Singh N, Dawnay A, Skates SJ, Parmar M, Jacobs I (2009) Sensitivity and specificity of multimodal and ultrasound screening for ovarian cancer, and stage distribution of detected cancers: results of the prevalence screen of

the UK Collaborative Trial of Ovarian Cancer Screening (UKCTOCS). Lancet Oncol 10: 327-340.

Minato H, Shimizu M, Hirokawa M, Fujiwara K, Kohno I, Manabe T (1998) Adenocarcinoma in situ of the fallopian tube. A case report. Acta Cytol 42: $1455-1457$.

Ohta H, Otsuka I, Ueda K, Lin YH, Akimoto N, Sugibayashi R, Furusawa Y, Suzuki M, Koi H, Kushanishi H, Shimizu Y, Kameda S, Hoshi K, Kushima M (2009) A case of a mixed endometrioid and clear cell adenocarcinoma arising from the fimbria of the Fallopian tube (in Japanese). Kanto J Obstet Gynecol 46: 367-372.

Otsuka I, Takahashi S, O’uchi K, Akimoto N, Hanari K, Ogaki Y, Enatsu YH, Takigawa A, Takaya H, Tanaka A, Kaseki H, Yamada T (2010) Clinicopathological features of endometrial carcinoma in tamoxifen- and toremifene-treated breast cancer patients (in Japanese). Gan To Kagaku Ryoho 37: 279-283.

Piek JM, van Diest PJ, Zweemer RP, Jansen JW, Poort-Keesom RJ, Menko FH, Gille JJ, Jongsma AP, Pals G, Kenemans P, Verheijne RH (2001) Dysplasic changes in prophylactically removed Fallopian tubes of women predisposed to developing ovarian cancer. J Pathol 195: 451-456.

Powell CB, Kenley E, Chen LM, Crawford B, McLennan J, Zaloudek C, Komaromy M, Beattie M, Ziegler J (2005) Risk-reducing salpingooophorectomy in BRCA mutation carriers: role of serial sectioning in the detection of occult malignancy. J Clin Oncol 23: 127-132.

Prat J (2012) New insights into ovarian cancer pathology. Annal Oncol 23(suppl 10): x111-x117.

Roh MH, Yassin Y, Miron A, Mehra KK, Mehrad M, Monte NM, Mutter GL, Nucci MR, Ning G, McKeon FD, Hirsch MS, Wa X, Crum CP (2010) High-grade fimbrial-ovarian carcinomas are unified by altered p53, PTEN and PAX2 expression. Mod Pathol 23: 1316-1324.

Seidman JD, Zhao P, Yemelyanova A (2011) 'Primary peritoneal' high-grade serous carcinoma is very likely metastatic from serous tubal intraepithelial carcinoma: assessing the new paradigm of ovarian and pelvic serous carcinogenesis and its implications for screening for ovarian cancer. Gynecol Oncol 120: 470-473.

Shih IM, Kurman RJ (2004) Ovarian tumorigenesis. A proposed model based on morphological and molecular genetic analysis. Am J Pathol 164: 1511-1518.

Stirling D, Evans DGR, Pichert G, Shenton A, Kirk EN, Rimmer S, Steel CM, Lawson S, Busby-Earle RMC, Walker J, Lalloo FI, Eccles DM, Lucassen AM, Porteous ME (2005) Screening for familial ovarian cancer: failure of current protocols to detect ovarian cancer at an early stage according to the International Federation of Gynecology and Obstetrics system. J Clin Oncol 23: 5588-5596.

Suzuki M, Suzuki T, Matsuura M, Iwasaki M, Tanaka R, Ito E, Fujii M, Saito T (2010) Prediction of histologic type and lymph node metastasis for advanced ovarian cancer on uterine cervical and endometrial cytology. Acta Cytol 54: 575-581.

Takashina T, Ono M, Kanda Y, Sagae S, Hayakawa O, Ito E (1988) Cervicovaginal and endometrial cytology in ovarian cancer. Acta Cytol 32: 159-162.

Takeshima N, Hirai Y, Yamauchi K, Hasumi K (1997) Clinical usefulness of endometrial aspiration cytology and CA-125 in the detection of fallopian tube carcinoma. Acta Cytol 41: 1445-1450.

Tsuda H, Kawabata M, Yamamoto K, Inoue T, Umesaki N (1997) Prospective study to compare endometrial cytology and transvaginal ultrasonography for identification of endometrial malignancies. Gynecol Oncol 65: 383-386. van Nagell Jr JR, DePriest PD, Ueland FR, DeSimone CP, Cooper AL, McDonald JM, Pavlik EJ, Kryscio RJ (2007) Ovarian cancer screening with annual transvaginal sonography. Findings of 25,000 women screened. Cancer 109: 1887-1896.

Vikki M, Pukkala E, Hakama M (1998) Risk of endometrial, ovarian, vulvar, and vaginal cancers after a positive cervical cytology followed by negative histology. Obstet Gynecol 92: 269-273.

(c) (i) (2) This work is licensed under the Creative Commons (c) Attribution-NonCommercial-Share Alike 3.0 Unported License. To view a copy of this license, visit http://creativecommons. org/licenses/by-nc-sa/3.0/ 